\title{
PENTINGNYA OLAHRAGA BAGI LANSIA
}

\author{
Oleh: Suryanto \\ Dosen Jurusan Pendidikan Kesehatan dan Rekreasi FIK-UNY
}

\begin{abstract}
Abstrak
Salah satu upaya untuk menjaga, meningkatkan kesehatan dan kesegaran jasmani bagi lansia (lanjut usia) adalah dengan melakukan olahraga.

Olahraga bagi lansia bila dilakukan dengan terprogram akan mempunyai beberapa manfaat, diantaranya adalah untuk mempertahankan kesehatan, meningkatkan kekuatan otot jantung, meningkatkan sirkulasi darah dalam tubuh, menurunkan kadar lemak, menguatkan otot-otot tubuh, mengurangi stress dan ketegangan batin, meningkatkan sistem kekebalan tubuh. Apabila latihan olahraga tidak tepat akan menimbulkan risiko yang lebih berbahaya.

Dalam memperlambat terjadinya gangguan dan penurunan, terutama ukuran dan kekuatan otot salah satunya dengan latihan penguatan secara teratur. Program latihan penguatan dapat mengganti sejumlah besar otot yang berkurang. Untuk latihan penguatan yang aman dan produktif perlu persiapan dan menjalankan setiap sesi latihan dengan sempurna.
\end{abstract}

Kata kunci: olahraga, lansia

Pada saat ini banyak lansia (lanjut usia) yang melakukan olahraga (aktivitas jasmani), baik secara perorangan maupun kelompok. Olahraga yang dilakukan biasanya jalan kaki, jogging, senam, berenang, bersepeda, dan lain sebagainya. Tujuan para lansia melakukan olahraga ada bermacam-macam, misalnya untuk menjaga kesehatan, menjaga dan meningkatkan kebugaran baik fisik maupun mental, kesenangan dan lain sebagainya.

Lansia di Indonesia tidak semuanya dapat melakukan olahraga, karena terhambat berbagai keterbatasan. Di samping itu jumlah lansia yang setiap tahunnya mengalami peningkatan memerlukan pelayanan yang lebih baik, terutama dari keluarga maupun pemerintah. Adapun data peningkatan lansia dari tahun ke tahun menurut Susilo Bambang Yudhoyono yang dikutip oleh Kedaulatan Rakyat (2010: 28) menyebutkan bahwa tahun 1970 berjumlah 5,3 juta orang, tahun 1990 berjumlah 12,7 juta orang, tahun 2.000 
berjumlah 14,4 juta orang, dan tahun 2008 mencapai 19,5 juta orang. Menurut Sulistiyo yang dikutip oleh Kedaulatan Rakyat (2010: 2) di Daerah Istimewa Yogyakarta (DIY) yang luasnya 3.185,81 Km dihuni oleh 3,33 juta jiwa dengan penduduk lansia sejumlah 389.347 jiwa. Dari jumlah 389.347 yang mendapat jaminan sosial lanjut usia (JSLU) di DIY baru 500 lansia. Sebanyak 21.941 dari 389.347 penduduk lansia di DIY dalam kondisi terlantar. Mereka tinggal dalam keluarga miskin dan Pemerintah Provinsi tidak bisa berbuat banyak karena keterbatasan anggaran.

Berdasarkan data di atas, lansia di DIY cukup banyak, sehingga para lansia perlu dibekali perilaku hidup sehat, salah satunya adalah perilaku hidup sehat lansia terhadap kesegaran jasmani. Menurut penelitian Suryanto dan Suharjana (2004: 21) perilaku hidup sehat lansia terhadap kesegaran jasmani di Dusun Karanggawang, Desa Mororejo, Kecamatan Tempel, Kabupaten Sleman termasuk dalam Kategori Tidak Baik. Kemungkinan para lansia belum atau kurang memahami manfaat memiliki kesegaran jasmani yang baik atau sangat baik. Kemungkinan yang lain adalah para lansia melakukan olahraga biasanya tidak mengetahui program latihan yang telah ditentukan, padahal program itu sangat penting, karena latihan yang tidak sesuai dengan programnya latihan itu tidak mempunyai pengaruh terhadap tubuh.

\section{Pengertian Lansia}

Dari para ahli terdapat beberapa pengertian mengenai lansia. Menurut Angga (2010: 1) lansia adalah dimana seseorang mengalami pertambahan umur disertai dengan penurunan fungsi fisik yang ditandai dengan penurunan massa otot serta kekuatannya, laju denyut jantung maksimal, peningkatan lemak tubuh, dan penurunan fungsi otak.

Menurut ilmu gerontologia, setiap orang memiliki tiga macam umur: (1) Umur kronologis yaitu umur yang dihitung dari jumlah tahun yang sudah dilewati seseorang, misalnya 50 tahun, 60 tahun, dan sebagainya; (2) Umur biologis yaitu umur yang ditentukan berdasarkan kondisi tubuh. Hal ini dapat terjadi jika seseorang menjadi tua karena ia merasa tua; (3) Umur psikologis yaitu umur yang diukur berdasarkan sejauh mana kemampuan seseorang merasakan dan bertindak. Hal ini dapat terjadi pada seorang yang sudah berusia 80 tahun tapi merasa lebih muda dari orang yang di bawah umurnya. Ada beberapa Negara menetapkan usia kronologis yang berbeda bagi lansia. Di Indonesia, seseorang dianggap lansia ketika ia pensiun dari pekerjaannya pada usia 55 tahun. Namun di Amerika Serikat seseorang dikategorikan sebagai lansia pada usia 77 tahun yang didahului massa pra lansia, yaitu usia 69-76 tahun. Pada orang Jepang kesuksesan justru dimulai pada usia 60 tahun, dan banyak wanita Jepang yang masih bekerja pada usia 60 tahun ke atas, sedangkan WHO (Organisasi Kesehatan Dunia) menetapkan usia 60 tahun sebagai titik awal seseorang memasuki massa lansia (Angga, 2010:1).

Pendapat lain mengatakan bahwa lansia adalah periode dimana organisme telah mencapai kemasakan dalam ukuran dan fungsi serta telah menunjukkan kemunduran sejalan dengan waktu. Ada beberapa pendapat mengenai usia kemunduran yaitu ada yang

MEDIIKORA Vol. VI, No. 1, April 2010: 23 - 30 
menetapkan 60 tahun, 65 tahun dan 70 tahun (Akhmadi, 2009:1). Sadoso Sumosardjuno yang dikutip oleh Indri Gautama dkk. (tt:1) menyatakan bahwa menua atau menjadi tua adalah proses alami yang dialami setiap orang. Namun batasan atau kategori usia tua masih relatif. Ada seorang yang sudah berusia 80 tahun masih tetap sehat dan aktif bekerja, tapi ada juga yang baru berusia 45 tahun sudah tidak kuat bekerja karena menderita suatu penyakit. Meski begitu badan kesehatan dunia WHO menggunakan batasan lansia secara kronologis pada usia 60 tahun ke atas dan menganjurkan negara-negara anggotanya untuk menjadikan sebagai patokan baku demi memudahkan dalam menyusun kebijakan masalah kesehatan oleh WHO.

Menurut International Institute on Aging (INIA), World Health Organization, Malta (1998) penyebab timbulnya kesehatan pada lansia menurut Hardywinoto dan Tony Setiabudhi (2005: 128-129) adalah sebagai berikut:

1. Umur harapan hidup bertambah panjang.

2. Morbiditas meningkat.

3. Lanjut usia mengalami beban ganda, yaitu mengidap penyakit infeksi dan kronis.

4. Bertambahnya kerusakan yang terjadi yang diakibatkan penyakit atau kecacatan, menimbulkan ketergantungan.

5. Faktor-faktor lainnya, seperti: (a) Psikososial, (b) Lingkungan, misalnya polusi, (c) Kondisi pemukiman dan pekerjaan, (d) Makanan, (e) Status sosio-ekonomi, (f) Perilaku, (g) Tingkat pendidikan dan buta huruf, (h) Stres, (i) Mekanisme kegiatan untuk mengatasi masalah, (j) Jaringan sosial, (k) Status pernikahan lanjut usia, (l) Penilaian terhadap diri sendiri, (m) Perawatan, dan (n) Akses kepada fasilitas kesehatan.

\section{Manfaat Olahraga bagi Lansia}

Masalah yang dihadapi para lansia adalah penurunan organ secara sistemik, seperti penurunan fungsi ginjal, fungsi jantung, mata maupun fungsi kognitif (intelektual), yang harus diperhatikan sebelum merencanakan diet dan olahraga yang sesuai. Perubahanperubahan tersebut menurut Jeffry Tenggara (2009: 3-4) dapat diuraikan sebagai berikut: 1. Jantung

Jantung adalah organ maskular (sebagian besar adalah otot) yang berperan dalam memompa darah ke seluruh tubuh. Jantung yang mengalami beban berat secara kronik akibat penyakit akan mengalami pembesaran otot. Berbeda dengan otot bisep yang bisa dilatih hingga membesar dan bertambah kuat, pembesaran otot jantung akan mengakibatkan kelelahan otot dan failure dalam memompa darah. Apabila hal ini telah mencapai batas ambang yang dapat ditoleransi akan menimbulkan keluhan seperti lelah, sesak nafas, dan pada kondisi berat dapat terjadi henti jantung.

2. Ginjal

Ginjal adalah organ yang memiliki fungsi utama untuk menyaring darah dan 
membuang racun hasil metabolisme maupun racun yang kita konsumsi secara tidak sengaja. Pada lansia sehat, ginjal akan tetap berfungsi baik. Namun bila ginjal mengalami kerusakan yang diakibatkan terutama oleh hipertensi, kencing manis, infeksi berulang, atau batu ginjal, akan terjadi perubahan dalam struktur dan fungsinya. Jaringan parut akan menumpuk sebagai respon dari perbaikan kerusakan, sehingga filter yang ada akan tidak berfungsi baik. Akibat dari gagal ginjal adalah sesak, muntah hebat hingga kejang yang mengharuskan untuk dilakukan cuci darah.

3. Kognitif otak

Pada lansia, umum (namun tidak selalu) terjadi penurunan fungsi intelektual/ kognitif. Penyakit yang sering kita lihat adalah Kepikunan/Demensia, Parkinsonisme, Stroke dengan berbagai gejalanya. Beberapa kondisi di atas memang dapat dicegah dan salah satunya adalah dengan latihan fisik teratur.

4. Gangguan penglihatan dan pendengaran.

Pada lansia beberapa penyakit yang sering dijumpai adalah katarak, gangguan retina karena kencing manis dan hipertensi. Penurunan fungsi mata dan telinga harus diperhatikan dalam merencanakan olahraga, karena akan berpengaruh dalam sistem keseimbangan dan resiko jatuh pada lansia.

Gangguan atau penurunan fungsi organ di atas harus terlebih dahulu dimengerti dan disesuaikan untuk merencanakan latihan fisik pada lansia. Latihan yang salah atau tidak tepat akan menimbulkan risiko yang lebih berbahaya, namun dengan latihan yang tepat, manfaat latihan bagi lansia akan juga sangat signifikan.

Angga (2010: 1) menyatakan bahwa adakalanya pada usia lanjut seseorang menderita penyakit tertentu. Ini tak berarti dia tidak boleh berolahraga. Pada umumnya dia dapat melanjutkan kebiasaan berolahraga, hanya dia perlu membicarakan dengan dokternya, apakah olahraga yang dipilihnya cocok dan tidak mempengaruhi penyakitnya.

Pada beberapa penyakit pemilihan olahraga disesuaikan penyakitnya. Pada radang sendi, misalnya olahraga terlalu banyak menggerakkan sendi mungkin akan menimbulkan rasa nyeri. Namun sendi yang meradang juga tak boleh dibiarkan tak bergerak karena dapat menimbulkan sendi menjadi kaku. Salah satu pilihan yang cukup baik untuk penderita radang sendi kronik adalah berenang. Pada penyakit jantung koroner, dokter akan menganjurkan olahraga sesuai dengan keadaan pasien. Biasanya olahraga yang dianjurkan adalah olahraga yang bersifat aerobik. Jenis olahraga aerobik di antaranya adalah jalan kaki, bersepeda, dansa, berenang, dan golf. Pada penderita penyakit paru obstruktif menahun olahraga juga bermanfaat. Olahraga pada penderita penyakit paru obstruktif menahun dapat meningkatkan kualitas hidup penderita. Pada umumnya lansia dapat tetap berolahraga, memang ada beberapa penyakit yang mengharuskan penderita istirahat total di tempat tidur, misalnya penyakit infark jantung akut. Namun biasanya istirahat total ini hanya beberapa hari. Secara bertahap penderita akan dilatih mobilisasi dan kemu- 
dian akan dianjurkan untuk berolahraga ringan (Angga, 2010: 1-2).

Manfaat olahraga untuk lansia menurut Angga (2010: 2) adalah sebagai berikut:

1. Meningkatkan kekuatan otot jantung, memperkecil resiko serangan jantung.

2. Melancarkan sirkulasi darah dalam tubuh, sehingga menurunkan tekanan darah dan menghindari penyakit tekanan darah tinggi.

3. Menurunkan kadar lemak dalam tubuh, sehingga mem-bantu mengurangi berat badan yang berlebih dan terhindar dari obesitas.

4. Menguatkan otot-otot tubuh, sehingga otot tubuh men-jadi lentur dan terhindar dari penyakit rematik.

5. Meningkatkan sistem kekebalan tubuh, sehingga ter-hindar dari penyakit-penyakit yang menyerang kaum lansia.

6. Mengurangi stress dan ketegangan pikiran.

7. Latihan atau olahraga dengan intensitas sedang dapat memberikan keuntungan bagi para lansia melalui berbagai hal, antara lain status kardiovaskuler, resiko fraktur, abilitas fungsional dan proses mental.

8. Latihan menahan beban (weight bearing exercise) yang intensif, misalnya berjalan adalah yang paling aman, murah dan paling mudah serta sangat bermanfaat bagi sebagian besar lansia.

Menurut Akhmadi (2008: 1-2) agar lanjut usia tetap sehat, bahagia, berguna dan berkualitas, maka beberapa hal harus diperhatikan. Ada sebuah singkatan yang sangat baik yang menggambarkan kunci menuju lansia yang sehat adalah B-A-H-A-G-I-A. Kata tersebut mengandung makna yang sangat dalam untuk menjaga tubuh agar tetap sehat dan berguna, sedangkan kepanjangan dari B-A-H-A-G-I-A adalah B= Berat Badan, $\mathrm{A}=$ Aturlah, $\mathrm{H}=$ Hindari, $\mathrm{A}=$ Agar, $\mathrm{G}=\mathrm{Gairah}, \mathrm{I}=\mathrm{Ikuti}$, dan $\mathrm{A}=$ Awasi. Adapun penjabaran dari tiap huruf yang terkandung di dalamnya secara rinci adalah sebagai berikut:

1. Huruf $\mathbf{B}$ yaitu mengandung makna Berat Badan (BB) berlebihan supaya dihindarkan.

Agar berat badan dapat dikontrol dengan baik, maka minimal lansia dapat mengontrol sekali sebulan di posyandu setempat.

2. Huruf $\mathbf{A}$ aturlah makan yang sesuai kebutuhan tubuh.

Makanlah makanan dengan gizi yang seimbang yaitu zat gizi yang sesuai tubuh lansia. Mengurangi konsumsi lemak adalah salah satu tindakan yang penting. Langkah tersebut juga akan membantu mengurangi pemasukan kalori.

3. Huruf $\mathbf{H}$ yaitu hindari faktor-faktor resiko penyakit jantung iskemik/koroner.

Ada beberapa faktor yang yang diduga sebagai penyebab dari gangguan penyakit jantung, yaitu: merokok, tekanan darah tinggi, kolesterol tinngi, penyakit gula, kegemukan, kurang gerak fisik, dan tekanan batin. 
4. Huruf A yaitu agar terus merasa berguna dengan mempunyai kegiatan/hobi yang bermanfaat.

Untuk mengisi waktu luang bagi lansia alangkah baiknya kalau menyalurkan hobi, seperti ketika waktu masih muda. Salurkan hobi tersebut pada hal-hal yang menyehatkan dan bermanfaat.

5. Huruf $\mathbf{G}$ yaitu gairah hidup akan semarak jika kegiatan tersebut dilakukan bersama.

Untuk dapat hidup bergairah dan bersemangat, maka kondisi tubuh agar tetap fit dan sehat. Agar tubuh fit dan sehat, lakukanlah olahraga yang ringan tetapi teratur. Berikut ini ada beberapa alasan agar kita berolahraga.

Berbagai penelitian memperlihatkan bahwa olahraga yang teratur dapat membantu menurunkan risiko terkena penyakit Jantung, Stroke/lumpuh, Diabetes, Darah tinggi, dan Osteoporosis/rapuh tulang. Namun demikian, minta petunjuk dokter sebelum anda mulai menjalankan program olahraga anda. Olahraga bersifat aerobik cenderung memberi keuntungan yang terbesar, namun beberapa diantaranya, seperti jogging sering terlalu berat untuk persendian bagi orang yang mulái lansia. Tetapi ada beberapa jenis olahraga yang menguntungkan namun tidak terlalu sulit untuk dikerjakan oleh lansia. Olahraga tersebut antara lain: berenang, berjalan, senam. Olahraga yang baik dapat mempengaruhi sebagai berikut:

a. Memperlambat proses degenerasi karena perubahan lansia.

b. Mempermudah kesehatan jasmani dalam kehidupan.

c. Berfungsi melindungi, yaitu memperbaiki tenaga cadangan ketika sakit.

6. Huruf I yaitu ikuti nasehat dokter dan hindari situasi tegang.

Saran-saran yang dapat diberikan oleh dokter, perawat atau tenaga kesehatan lainnya adalah:

a. Berolahraga teratur agar tetap sehat dan bugar.

b. Makan makanan yang banyak mengandung serat.

c. Makan buah-buahan tetapi batasi untuk mengkon-sumsi buah apukat, sawo, pisang, durian, karena mengandung kalori yang tinngi.

d. Biasakan makan pagi.

e. Hindari tekanan batin yang tidak perlu.

7. Huruf A yaitu awasi kesehatan dengan memeriksakan badan secara teratur.

Pemeriksaan kesehatan secara berkala dan konsultasi merupakan kunci keberhasilan dari upaya pemeliharaan kesehatan lansia. Dengan pemeriksaan berkala dapat terdeteksinya penyakit sedini mungkin, sehingga mengurangi faktor resiko yang berat. Rahasia lain agar tetap sehat dan prima menurut Akhmadi (2008: 3) adalah olahraga mental yaitu memberdayakan pikiran sama pentingnya dengan olahraga fisik. Menurut Jeffry Tenggara (2009: 2-3) aktivitas fisik secara rutin memiliki dampak yang baik untuk meningkatkan kesehatan lansia, namun aktivitas fisik yang salah 
akan menimbulkan risiko lebih besar dari manfaat yang diperoleh. Adapun lansia yang sehat masih terjadi penurunan kadar massa otot hingga $40 \%$ dan digantikan oleh jaringan lemak. Selain terjadi penurunan secara kuantitatif dari massa otot, kualitas kekuatan otot yang ada juga turun. Perubahan lain dalam sistem muskuloskeletal pada lansia juga mencakup perubahan kekuatan dan komposisi tulang. Kehilangan massa tulang adalah garmbaran khas lansia sebagai akibat kehilangan mineral tulang, perubahan sistem hormonal, penurunan aktivitas dan kurangnya paparan sinar matahari.

Andriewongso (2008: 1) menyatakan bahwa olahraga sangat penting untuk menjaga kesehatan. Dengan berolahraga meski itu hanya jalan kaki santai bisa mencegah beragam penyakit bahkan kepikunan. Bagi mereka yang rajin berolahraga di hari tuanya akan menikmati efek awet muda sekaligus awet sehat.

\section{Menguatkan Tubuh dengan Aman pada Usia 50+}

Westcott, W.L., dan Baechle, T. R., yang dikutip oleh Eri Desmarini Nasution (1999: VII) menyatakan bahwa ukuran dan kekuatan otot berkurang seiring dengan penuaan, yang mengakibatkan melemahnya fisik dan berbagai masalah kemunduran. Untungnya anda dapat menghindari berkurangnya kekuatan otot dengan melakukan latihan penguatan secara teratur. Lebih untung dari itu, anda dapat mengganti sejumlah besar otot yang berkurang dalam waktu yang relatif singkat melalui program latihan penguatan yang sederhana. Berdasarkan hasil penelitian yang dilakukan selama lima tahun mengenai efek latihan penguatan secara teratur pada orang dewasa dan lanjut usia yang hidup secara pasif. Total respoden sejumlah 1.132 pria dan wanita ikut berpartisipasi dalam program kebugaran selama 2 bulan, yang terdiri atas latihan penguatan 30 menit pada 12 mesin beban sebanyak dua atau tiga kali seminggu. Rata-rata orang dewasa ( 21 hingga 40 tahun) dan setengah baya (41 hingga 60 tahun) menambah berat otot sebanyak 2.3 pon, dan yang lansia (61 hingga 80 tahun) menambah 2.4 pon. Setelah peserta meneruskan program latihan penguatan, Contohnya, setelah latihan penguatan selama 18 bulan, Dick Carey (usia 60 tahun) menambah 5 pon otot, mengurangi 17 pon lemak, dan meningkatkan kecepatan ayunan permainan golfnya.

Adapun menurut Westcott, W.L., dan Baechle, T.R., yang dikutif oleh Eri Desmarini Nasution (1999: 21) latihan kekuatan yang aman dan produktif, lansia harus bersiapsiap dan menjalankan setiap sesi latihan dengan sempurna, yaitu:

1. Mendapatkan persetujuan dokter.

2. Berlatih dalam ruangan yang lapang.

3. Memakai pakaian yang fungsional.

4. Mempertahankan keseimbangan cairan yang ideal.

5. Menggunakan baban latihan yang tepat.

6. Mengikuti progresi latihan yang pantas.

7. Menggunakan teknik yang benar. 
8. Berlatih dengan seorang pengamat pada latihan yang tepat.

9. Menekankan pada kontrol gerakan.

10. Mengembangkan kebiasaan latihan yang baik.

Namun perlu dipahami bahwa olahraga pada lansia hanya sebatas untuk mempertahankan kesehątan dan bukan untuk mencari prestasi dalam pertandingan (Prima, 2008: 1).

\section{KESIMPULAN}

Olahraga bagi lansia merupakan sesuatu yang sangat penting, karena olahraga dapat mendukung dalam melakukan aktivitas sehari-hari. Untuk itu para lansia perlu meluangkan waktu atau menjadwalkan latihan untuk melakukan olahraga secara teratur. Di samping itu yang perlu diperhatikan adalah para lansia sebelum melakukan olahraga perlu berbicara dengan dokter, apakah dokter menyetujui aktivitas tersebut atau tidak.

\section{DAFTAR PUSTAKA}

Akhmadi. (2008). Menjaga Kesehatan Lanjut Usia Agar Tetap Prima. Yogyakarta: FK UGM. http://akhmadi.multiply.com/journal/item/10

(2009). Permasalaban Lanjut Usia (Lansia). http://www.rajawana.com/artikel/ kesehatan/326.permasalahan-lanjut.

Andriewongso. (2008). Olabraga Perpanjang Usia. http://www.andriewongso.com/ awartikel-2152-AW_Corner-Olahra.

Angga. (2010) Lansia dan Olabraga. http://anggaway89.wordpress.com/2010/05/24/lansiadan.olahraga/

Eri Desmarini Nasution. (1999). Kembali Bugar setelah Lima Puluh. (Terjemahan dari Westcott Wayne L. dan Baechle Thomas R.). Jakarta: PT Raja Grafindo Persada.

Indri Gautama, dkk. Lansia Sehat Siap Fisik, Mental dan Finansial. http:// www.sahabatsurgawi. net/berita_lansia-sehat.html

Hardywinoto dan Tony Setiabudhi. (2005). Panduan Gerontologi Tinjauan dari Berbagai Aspek. Jakarta: PT Gramedia Pustaka Utama.

Jeffry Tenggara. (2009). Elderly Exercise- Olabraga untuk Lanjut Usia, Bagian I. Jakarta: FKUIRSCM. http://www.dennysantoso.com/elderly-exercise-olahraga-untuk-lanjut.

Prima. (2008). Lansia Harus Terus Lakukan Gerak Badan. http://www.waspada.co.id/ index2.php?option=com_content\&do_pd.

Susilo Bambang Yudhoyono. “Anggaran Lansia Dinaikkan” Kedaulatan Rakyat. Kamis Wage 10 Juni 2010.

Sulistiyo. "21 Ribu Lansia di DIY Terlantar" Kedaulatan Rakyat. Sabtu Wage 5 Juni 2010.

Suryanto dan Suharjana. (2004). "Perilaku Hidup Sehat Lanjut Usia di Dusun Karanggawang Desa Mororejo, Kecamatan Tempel, Kabupaten Sleman". Laporan Penelitian. Yogyakarta: FIK UNY.

MEDIIKORA Vol. VI, No. 1, April 2010: 23 - 30 